\title{
O DISCURSO INSTITUCIONAL NA INICIAÇÃO CIENTÍFICA E TECNOLÓGICA: MUSEU CASA GUIMARÃES ROSA E STJ SOB A ÓTICA DE ANALISTAS DE DISCURSO JUNIORES
}

\author{
RAFAEL BATISTA ANDRADE ${ }^{1}$
}

Instituto Federal de Minas Gerais - Campus Congonhas

Departamento: Área de Linguagens e Códigos

Av. Michael Pereira de Souza, 3007 - 36415-000 - Campinho - Congonhas - MG- Brasil

$\underline{\text { rafael.andradedifmg.edu.br }}$

Resumo. Neste trabalho, apresentamos duas análises que inauguraram o Grupo de Pesquisa sobre o Discurso Institucional na Iniciação Científica e Tecnológica. Tal prática colaborou para uma ampliação de programas que visam à formação de jovens cientistas a partir da formação de dois analistas de discurso juniores. Cada um deles estudou gêneros de discurso específicos que emergem de instituições diferentes: a) os gêneros de discurso entrevista e panfleto turístico do Museu Casa Guimarães Rosa; b) o gênero de discurso tweet do STJ. A pesquisa evidenciou a relevância dos estudos sobre o texto e o discurso no Ensino Básico, revelando a importância de se estudarem gêneros de discurso de diferentes instituições, públicas e privadas, nacionais e internacionais, com o fim de fomentar a formação de jovens cientistas no âmbito das Ciências da Linguagem.

Palavras-chave: discurso institucional; entrevista; panfleto turístico; tweet.

\begin{abstract}
In this work two analyses are presented that inaugurated the Research Group on Institutional Discourse in Scientific and Technological Initiation. This practice helps expand the programs aimed at training young scientists, namely two junior discourse analysts. Each of them studied specific discourse genres that emerge from different institutions: a) interview and tourist brochure of the Casa Guimarães Rosa Museum; b) the STJ tweet. The research showed the relevance of studies on text and discourse in Basic Education, revealing the importance of studying discourse genres of different institutions - public and private, national and international - in order to foster the formation of young scientists in the field of Language Sciences.
\end{abstract}

Keywords: institutional discourse; interview; tourist brochure; tweet.

\footnotetext{
${ }^{1}$ Doutor em Estudos Linguísticos pela UFMG. Docente no Ensino Básico, Técnico e Tecnológico no Instituto Federal de Minas Gerais, campus Congonhas (MG).
} 


\section{INTRODUÇÃO}

Ao discorrer sobre a noção de gêneros, Marcuschi (2008) lembra-nos que o estudo sobre essa categoria remonta ao menos cinco séculos, já que sua observação de forma sistemática foi iniciada por Platão. Não obstante, a nova visão de gênero que engloba uma análise do texto e do discurso desenvolveu-se na segunda metade do século $\mathrm{XX}$, sobretudo a partir dos estudos de Bakhtin (2011). Embora os alunos do Ensino Médio tenham conhecimento da noção de gênero de discurso desde o primeiro ano, e mesmo durante o Ensino Fundamental, constatamos que o trabalho realizado em sala de aula distancia-se de um desenvolvimento de pesquisa de iniciação científica. Por essa razão, criamos o Grupo de Pesquisa sobre o Discurso Institucional na Iniciação Científica e Tecnológica.

Neste artigo, apresentamos uma análise discursiva de uma entrevista e de um panfleto turístico do Museu Casa Guimarães Rosa e outra de seis tweets do primeiro trimestre de 2018 publicados em @STJnoticias. Tais estudos possuem uma peculiaridade. Eles foram desenvolvidos por analistas de discurso juniores sob a orientação de um especialista em Análise do Discurso. Com isso, esperamos mostrar a importância de pesquisas sobre o texto e o discurso no âmbito do Ensino Médio, uma vez que esse tipo de análise demonstra a importância de privilegiarmos núcleos de pesquisa de iniciação científica para esse público. Além disso, as análises demonstram o engajamento dos secundaristas por meio da projeção de um éthos de jovem cientista, já que os mesmos mostraram ter compreendido o fazer científico de parte das Ciências da Linguagem ao estudar produções verbais específicas no seio de suas respectivas condições sociais de produção.

Dividimos este trabalho em três seções com o fim de evidenciar as principais etapas da referida pesquisa. Na primeira, tratamos dos aspectos metodológicos e teóricos que nortearam a formação de dois analistas de discurso juniores. Na segunda, apresentamos as análises que demonstram a visão desses jovens cientistas em relação às produções científicas no âmbito das Ciências da Linguagem, mais especificamente em torno das teorias do texto e do discurso. Por fim, expomos as conclusões dessa investigação aliadas às suas possíveis contribuições para o tema da iniciação científica no Ensino Médio a partir de teorias do discurso, em particular, e de teorias linguísticas e literárias, em geral.

\section{METODOLOGIA E ASPECTOS TEÓRICOS}

As análises que serão apresentadas na seção subsequente possuem a particularidade de terem sido desenvolvidas por analistas de discurso juniores. Nesse sentido, os seus resultados são relevantes por revelar a desconstrução de estereótipos sobre os estudos científicos na área de Letras, mais especificamente na área de Linguística. Perseguimos, assim, o objetivo de oferecer aos participantes uma compreensão inicial do fazer científico de parte das Ciências da Linguagem. A começar pelo conhecimento de um breve percurso histórico de um dos principais campos disciplinares desse ramo científico durante encontros semanais no ano de 2018. Neles realizou-se o seguinte panorama sobre as abordagens teóricas que privilegiaríamos, pelo menos a princípio, no Grupo de Pesquisa sobre o Discurso Institucional na Iniciação Científica e Tecnológica. 
No final dos anos 1960, originou-se um campo disciplinar autônomo dentro das Ciências da Linguagem que tomou como objeto de estudo o discurso. Essa autonomia pode ser verificada pelo conjunto de noções, ferramentas e métodos específicos que reúne os traços fundamentais dessa nova abordagem transdisciplinar cujo resultado é a fundação do que hoje denominamos, em sentido amplo, Análise do Discurso. De acordo com Sarfati e Paveau (2014), o termo utilizado para definir essa disciplina é uma tradução da expressão elaborada por Harris, discourse analysis para o estudo da dimensão transfrástica, isto é, que ultrapassa a análise de frases.

Tradicionalmente, usa-se o termo Análise do Discurso associado à Escola francesa - ou, simplesmente, Análise do Discurso Francesa (ADF) - com o objetivo de definir essa disciplina de forma mais específica. Isso para diferenciá-la da corrente anglo-saxã e também da Linguística Textual. De acordo com Charaudeau e Maingueneau (2008), encontramos na primeira corrente uma abordagem sobre uma análise linguística voltada para a hierarquização dos textos conversacionais e uma abordagem etnometodológica. Já em relação à segunda corrente, os autores afirmam que suas principais características se resumem no objetivo de estudar a coesão e a coerência dos textos dentro de uma perspectiva textual-pragmática que perpassa aspectos microestruturais e macroestruturais (sequências, gêneros de discurso etc.). Já a ADF - ou a corrente da AD (tomada em sentido amplo) que praticamos no referido grupo - é uma disciplina de origem francesa que estuda as produções verbais no seio de suas condições sociais de produção, sendo que tais elementos são tomados como partes integrantes da significação e do modo de formação dos discursos.

Um dos principais autores dessa corrente da Análise do Discurso é o teórico francês Dominique Maingueneau. Em sua obra La philosophie comme institution discursive (2015), a noção de instituição ganhou destaque para evidenciar o fato de as instituições darem sentido à enunciação, por exemplo, à estrutura do campo e aos gêneros de discurso. Assumindo esses pressupostos teórico-metodológicos, Krieg-Planque (2014) dedicou-se ao estudo do discurso institucional: aqueles discursos que se engendram na/da enunciação de sujeitos engajados em partidos políticos, sindicatos, fundações, organizações públicas e privadas, instituições políticas e públicas nacionais, internacionais e transnacionais.

As propostas teórico-metodológicas desses autores, e de outros pesquisadores brasileiros e estrangeiros que com eles dialogam, motivaram o início desse grupo de pesquisa. Assim, foi proporcionado aos participantes um método de estudo que incentivou a sua formação enquanto jovens cientistas na área dos Estudos Linguísticos. Ao trabalhar com a análise de corpora específicos a partir de metodologias da Análise do Discurso Francesa, os dois analistas de discurso juniores testemunharam a relevância do trabalho científico com o texto e com o discurso, fornecendo contribuições originais para o Grupo de Pesquisa sobre o Discurso Institucional na Iniciação Científica e Tecnológica. A fim de dinamizar a apresentação das categorias de análise utilizadas nos textos dos corpora, optamos por apresentá-las de forma concomitante à apresentação das duas referidas análises. 


\section{ANÁLISE DOS CORPORA CONSTITUÍDOS POR CADA ANALISTA DE DISCURSO JÚNIOR}

O postulado que orientou o surgimento do Grupo de Pesquisa sobre o Discurso Institucional na Iniciação Científica e Tecnológica tem como base os estudos de KriegPlanque. Segundo a autora, "dentro de toda organização, existem pessoas e/ou serviços que possuem a tarefa de contribuir para a produção de discursos, em particular à luz de regularidades e de normas ${ }^{2}$ " (KRIEG-PLANQUE, 2014, p. 32) estabelecidas por determinados gêneros de discurso. Nessa perspectiva, vimos, durante os encontros do grupo, a necessidade de cada analista de discurso júnior dedicar-se a uma instituição a fim de elucidar fatos ainda pouco estudados no âmbito da Análise do Discurso em nível de iniciação científica. Por essa razão, esta seção foi subdividida em duas subseções. Em 2.1, dedicamo-nos à apresentação do trabalho que tomou por base uma parte da produção discursiva do Museu Casa Guimarães Rosa. Em 2.2, apresentamos o estudo que se voltou para uma parte da produção de discursos do Supremo Tribunal de Justiça (STJ). Tal divisão tem por objetivo mostrar os resultados obtidos de forma didática e, por tabela, revelar a autonomia que cada analista de discurso júnior teve durante o desenvolvimento de suas atividades de iniciação científica.

\section{Uma análise discursiva de uma entrevista e de um panfleto turístico do Museu Casa Guimarães Rosa}

Após termos compreendido o conceito de discurso institucional de acordo com a abordagem de Krieg-Planque (2014), deparamo-nos com a necessidade de formação de um corpus a fim de estudar parte dos discursos do Museu Casa Guimarães Rosa. A título de exemplo da constituição de um corpus conforme essa abordagem teóricometodológica, foi apresentado o trabalho de Andrade (2018). Nele o autor selecionou as intervenções dos representantes permanentes do Brasil, da Espanha e da França no Conselho de Segurança das Nações Unidas com o objetivo de classificá-las como um gênero de discurso diplomático.

Outro trabalho apresentado durante os encontros semanais do Grupo de Pesquisa sobre o Discurso Institucional na Iniciação Científica e Tecnológica foi o Semiótica, éthos e gêneros de discurso nas canções-poemas de Maria Bethânia (ANDRADE, 2015). Ainda que esse trabalho não tivesse uma relação direta com o escopo do estudo citado anteriormente, foi a partir de discussões em torno dessa obra e de outros artigos sobre o tema que realizamos uma visita ao Museu Casa Guimarães Rosa. Por essa razão, decidimos que o corpus dedicado ao estudo dessa instituição seria constituído de uma entrevista concedida exclusivamente ao referido grupo de pesquisa pelo coordenador do museu, o senhor Ronaldo Alves de Oliveira, no dia 16 e junho de 2018. Também consideramos como parte do corpus o folheto turístico Rosa dos tempos Rosa dos ventos, entregue durante a visita, por ele nos permitir um traço comparativo relevante no que tange ao discurso institucional.

Assim, no decorrer das atividades para a formação de um dos analistas do discurso juniores, lançamos a seguinte hipótese de trabalho: o museu possui a finalidade de

${ }^{2}$ Tradução livre de : «Dans toute organisation, il existe des personnes et / où des services qui sont en charge de contribuer à la production de discours, en particulier sous le jour de régularités et de normes ». 
divulgar a obra do escritor mineiro e, para isso, o discurso institucional (materializado, por exemplo, em uma entrevista) pode-se articular ao discurso midiático (ao utilizar, por exemplo, um panfleto turístico) para persuadir o seu destinatário. Logo, estes foram alguns questionamentos que nortearam esta parte da presente pesquisa: a instituição falaria por ela mesma? O tipo de discurso presente no panfleto seria mesmo um discurso publicitário?

Para responder essas questões, e outras mais pontuais, dividimos a apresentação de nossas análises em três partes. Em primeiro lugar, apresentamos a identidade museológica do Museu Casa Guimarães Rosa. Em seguida, mostramos os principais dados revelados pela análise da entrevista que nos foi concedida pelo coordenador do museu. Em terceiro lugar, tomamos como objeto de estudo um panfleto turístico da instituição a fim de analisar a sua cena englobante e a sua cena genérica. Por fim, estabelecemos uma comparação entre o papel que a entrevista e o panfleto turístico exercem na constituição de um discurso institucional.

\section{Identidade museológica do Museu Casa Guimarães Rosa}

A edificação do Museu Casa Guimarães Rosa caracteriza-se pela simplicidade de suas linhas arquitetônicas tão comuns em Minas Gerais em meados do século XIX. No entanto, destaca-se pela sua importância enquanto residência onde morou na infância o ilustre escritor João Guimarães Rosa, que divulgou universalmente a identidade da sua cidade e dos sertões de Minas. Para Cordisburgo, o Museu representa o marco da travessia de João Guimarães Rosa por este mundo e a importância para seus conterrâneos. Por tudo isso, indicamos o tombamento do Museu Casa Guimarães Rosa em nível municipal.

(Trecho final do parecer para o tombamento do Museu, elaborado pelo arquiteto José Ozório Caetano.)

Durante os encontros de nosso grupo de pesquisa, vimos que Maingueneau (2016) propõe uma análise voltada para a cena de enunciação. Esta possui três cenas interdependentes: a cena englobante, a cena genérica e a cenografia. Ao estudarmos a noção de cena englobante, percebemos a importância de se compreender o lugar da atividade do qual emerge o discurso com o qual trabalhamos. Isso porque essa categoria de análise permite ao pesquisador determinar o tipo de discurso predominante em seu corpus a partir do estudo de sua esfera de atividade, do seu campo discursivo/posicionamento e do seu lugar de atividade. Assim, apresentamos neste item dados que revelam aspectos sócio-históricos relevantes para uma análise discursiva dos textos do corpus, a começar por dados biográficos do escritor homenageado pelo referido museu.

João Guimarães Rosa foi um escritor, diplomata, contista, novelista e médico, considerado um dos maiores escritores brasileiros de todos os tempos. Nasceu no dia 27 de junho de 1908 em Cordisburgo, Minas Gerais. Cinquenta e nove anos mais tarde, sua cidade natal seria homenageada pelo escritor em seu discurso na cerimônia de posse da Academia Brasileira de Letras, quando ocupou a cadeira 2 desta organização. Em 
Cordisburgo, o escritor viveu até completar 9 anos de idade. Após algum tempo no internato de São João Del-Rei, Guimarães Rosa mudou-se para BH para estudar medicina. A residência de Rosa em Cordisburgo permaneceu sob posse da família até o ano de 1923, quando foi posteriormente vendida.

No ano de 1971, a propriedade foi novamente adquirida, dessa vez por meio do governador do Estado, Rondon Pacheco, que, a pedido da filha de Guimarães Rosa, Wilma Guimarães, compra a casa a qual é transferida posteriormente para o Instituto Estadual do Patrimônio Histórico e Artístico de Minas Gerais (IEPHA/MG). Logo após, foram feitas diversas pesquisas históricas para restauro da casa e coleta de acervo, em parceria principalmente com a família. Assim a inauguração do Museu ocorreu no dia 30 de março de 1974.

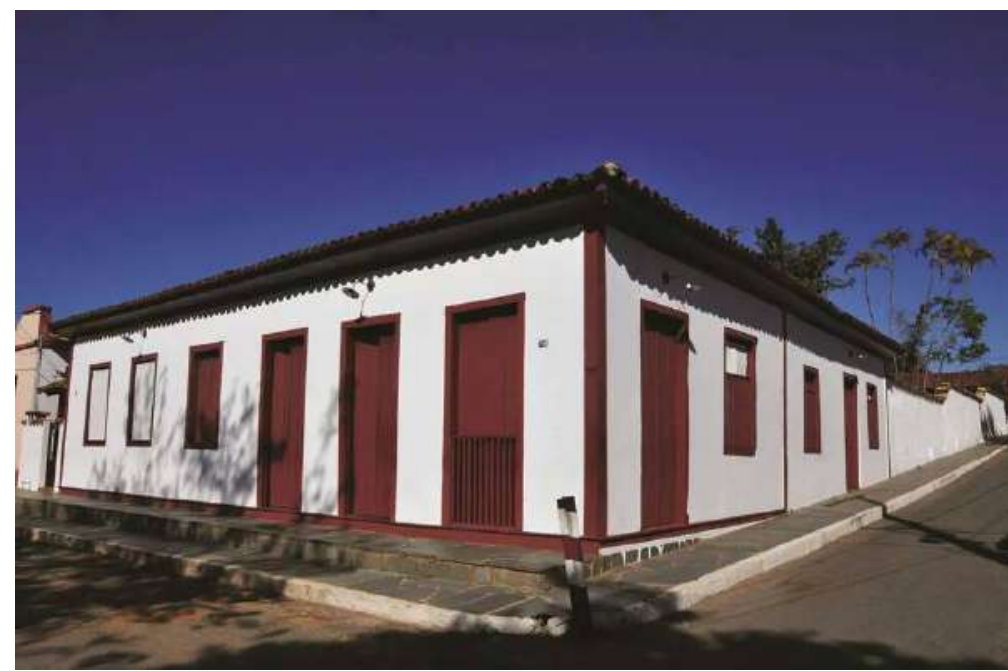

Figura 1 - Fachada Museu Casa Guimarães Rosa.

Atualmente, o Museu possui um acervo com cerca de setecentos documentos relativos à vida e à obra de Guimarães Rosa. Também formam parte desse acervo fotos, coleção de gravatas borboleta do escritor, todas as edições importantes dos livros de Guimarães Rosa, espada, bainha e diploma da Academia Brasileira de Letras, máquina de escrever, rascunhos e trabalhos, além de outros objetos pessoais. Além disso, no Museu, há um grupo de contadores de estórias chamado Miguilim, responsável pelo atendimento ao público e pela realização de narrações de trechos de livros de Guimarães Rosa. O grupo é formado por crianças e adolescentes que recebem uma formação relacionada à literatura rosiana e às técnicas relacionadas à narração de estórias. $\mathrm{O}$ nome do grupo nada mais é que uma homenagem ao personagem Miguilim, da obra Campo Geral.

É preciso ressaltar que a maior parte desses últimos dados exemplifica a noção de ritos legítimos, estudada em alguns encontros do grupo. Maingueneau (2006) utiliza esse termo para designar as atividades mais ou menos rotineiras através das quais se elaboram um texto. Para ele, a criação literária percorre diversos domínios: de elaboração (leituras, discussões...), de redação, de pré-difusão, de publicação. Nesse sentido, durante a visita ao museu, além da realização da entrevista que será analisada no próximo item, destacamos os dados apontados acima e finalizamos esta fase com as ilustrações abaixo 
que evidenciam os ritos legítimos de Guimarães Rosa enquanto parte constitutiva da identidade museológica referente ao Museu Casa Guimarães Rosa.

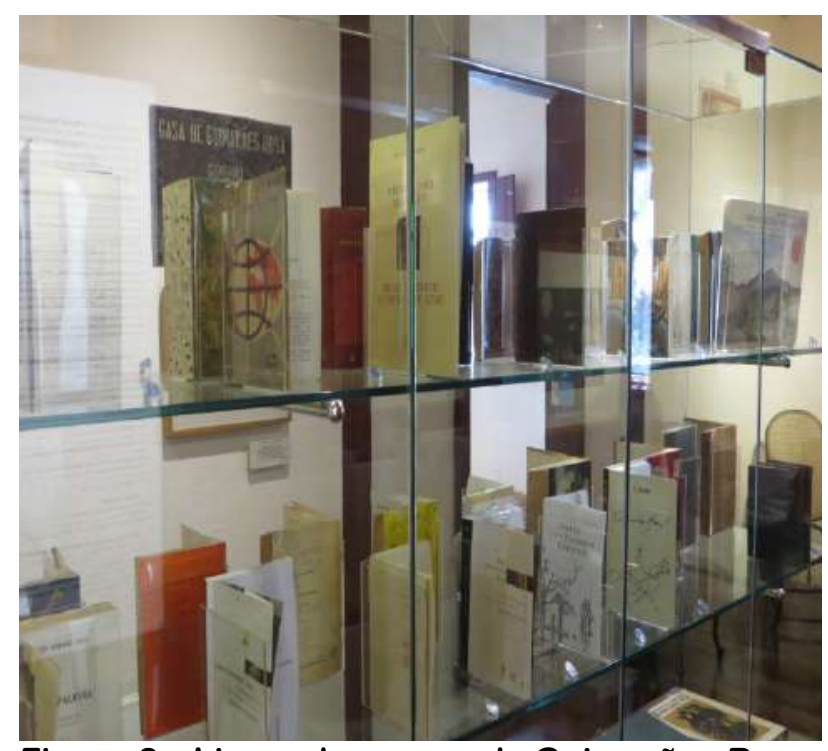

Figura 2 - Livros do acervo de Guimarães Rosa.

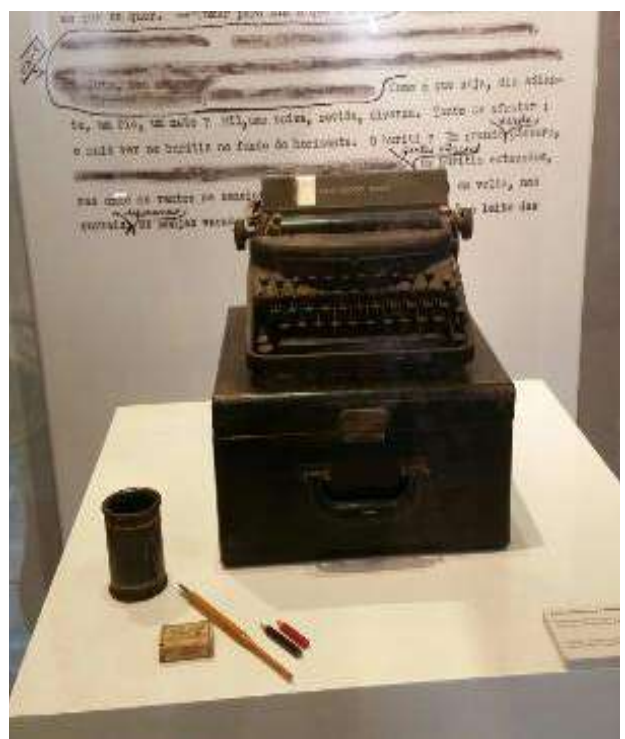

Figura 3 - Máquina de escrever que pertenceu a Guimarães Rosa.

\section{O museu enquanto meio promotor de um discurso: análise da entrevista}

A compreensão da existência de determinadas pessoas encarregadas pela produção de parte de discursos emergentes de uma organização (KRIEG-PLANQUE, 2014) levou-nos a realizar uma entrevista com o coordenador do Museu Casa Guimarães Rosa. Assim, no dia 16 e junho de 2018, entrevistamos o senhor Ronaldo Alves de Oliveira com o fim de formar a primeira parte do corpus desta pesquisa. A primeira regularidade que destacamos em relação a alguns trechos por nós analisados diz respeito à finalidade dessa instituição projetada por meio da construção de um éthos coletivo.

Para nós, uma norma ou uma regularidade do discurso institucional presente em partes da entrevista está na relação entre o uso da terceira pessoa do singular (o museu) em consonância com a primeira pessoa do plural. Trata-se de um caso similar às estratégias discursivas presentes nas intervenções de representantes permanentes do Brasil, da Espanha e da França no Conselho de Segurança das Nações Unidas (ANDRADE, 2018), conforme estudamos em alguns encontros do Grupo de Pesquisa sobre o Discurso Institucional na Iniciação Científica e Tecnológica. Veremos, pois, que, ao discorrer sobre a finalidade da instituição, o coordenador se refere a um "nós" que inclui todas as pessoas que contribuem para a funcionalidade do museu, valorizando um intertexto do próprio Guimarães Rosa. Logo, conseguimos evidenciar um traço do éthos coletivo do museu que "só é apreensível através dos comportamentos individuais nos quais ele vem se encarnar (são os indivíduos que, pelo seu comportamento, confirmam e consolidam os valores do grupo, atestando, ao mesmo tempo, sua adesão a esses valores coletivos)" (KERBRAT-ORECCHIONI, 2010, p. 119). 
Durante a entrevista, compreendemos que a principal característica do museu é ser um centro de informação e reflexão, um espaço destinado à propagação da cultura e do lazer. Com a criação do Museu Casa Guimarães Rosa, os visitantes puderam ter uma visão mais ampla e concreta sobre quem foi o escritor, e qual sua importância no contexto literário brasileiro. Nas entrelinhas do discurso, revelou-se a importância de se conhecer a obra de Guimarães Rosa a partir dessa instituição. Na entrevista, o coordenador responde a uma de nossas perguntas desta maneira, lançando mão de um "nós" para enfatizar o objetivo da instituição que coordena:

Qual é a missão do Museu? Divulgar a obra de Guimarães Rosa. $\underline{\mathrm{O}}$ principal foco nosso é que o visitante, ao vir conhecer o museu e ter a oportunidade de ouvir os contadores de estórias, que isso sirva de motivação para as pessoas lerem a obra. Porque o próprio Guimarães Rosa falava que as pessoas não tinham que preocupar com o escritor, e sim com a obra. O que mantém a obra viva é realmente se a obra é lida.

Além disso, em alguns trechos da entrevista, percebemos que a instituição, ao retratar a vida e a obra de Guimarães Rosa, destaca com enorme ênfase o período em que o escritor passou na cidade, ou seja, atribui um valor de extrema importância à infância do escritor, pois é a partir daí que começa a "inspiração" de Guimarães Rosa no que diz respeito à produção de suas obras nos anos seguintes. Esses dados retirados da referida entrevista nos permitiram compreender a particularidade de um museu em torno de uma personalidade da Literatura Brasileira. Isso porque o caráter institucional do museu emerge de um discurso literário, como defende Maingueneau.

Os escritores produzem obras, mas escritores e obras são, num dado sentido, produzidos eles mesmos por todo um complexo institucional de práticas. Deve-se assim atribuir todo o peso à instituição discursiva, expressão que combina inextricavelmente a instituição como ação de estabelecer, processo de construção legítima, e a instituição no sentido comum de organização de práticas e aparelhos. (MAINGUENEAU, 2006, p. 53; grifos do autor)

Portanto, fica nítido que os dois casos apresentados aqui evidenciam restrições do discurso institucional à entrevista concedida pelo coordenador do Museu Casa Guimarães Rosa. A visualização desses aspectos exigiu muito mais que a compreensão do gênero entrevista em sentido amplo. Isso porque, na terminologia maingueneauniana, a entrevista é uma cena genérica que possui um contrato próprio. Para nós, as estratégias que descrevemos neste item seguem as restrições de um jogo (MAINGUENEAU, 2016) em que a instituição possui um papel primordial. Assim, essas análises revelam o olhar de uma jovem cientista que projeta o éthos de analista de discurso júnior. Tais análises, aliás, responderam a um dos questionamentos lançados para a realização dessa parte da pesquisa: a instituição falaria por ela mesma? Constatamos que a instituição depende de pessoas que as representam para falar de si própria, uma vez que a construção de sua imagem nos discursos produzidos por ela mesma (éthos coletivo) depende de um comportamento individual. No caso, de uma entrevista do coordenador da referida instituição. 


\section{O discurso institucional no papel: análise de um panfleto turístico}

O museu, assim como várias outras instituições vinculadas à esfera social do turismo, utiliza o panfleto turístico como instrumento discursivo para divulgar o produto oferecido ou até mesmo a própria instituição. Como nosso objeto de estudo neste item é esse gênero de discurso, reproduzimos a seguir a capa do referido panfleto publicitário com o objetivo de apontar os efeitos que vinculam o Museu Casa Guimarães Rosa ao discurso institucional.

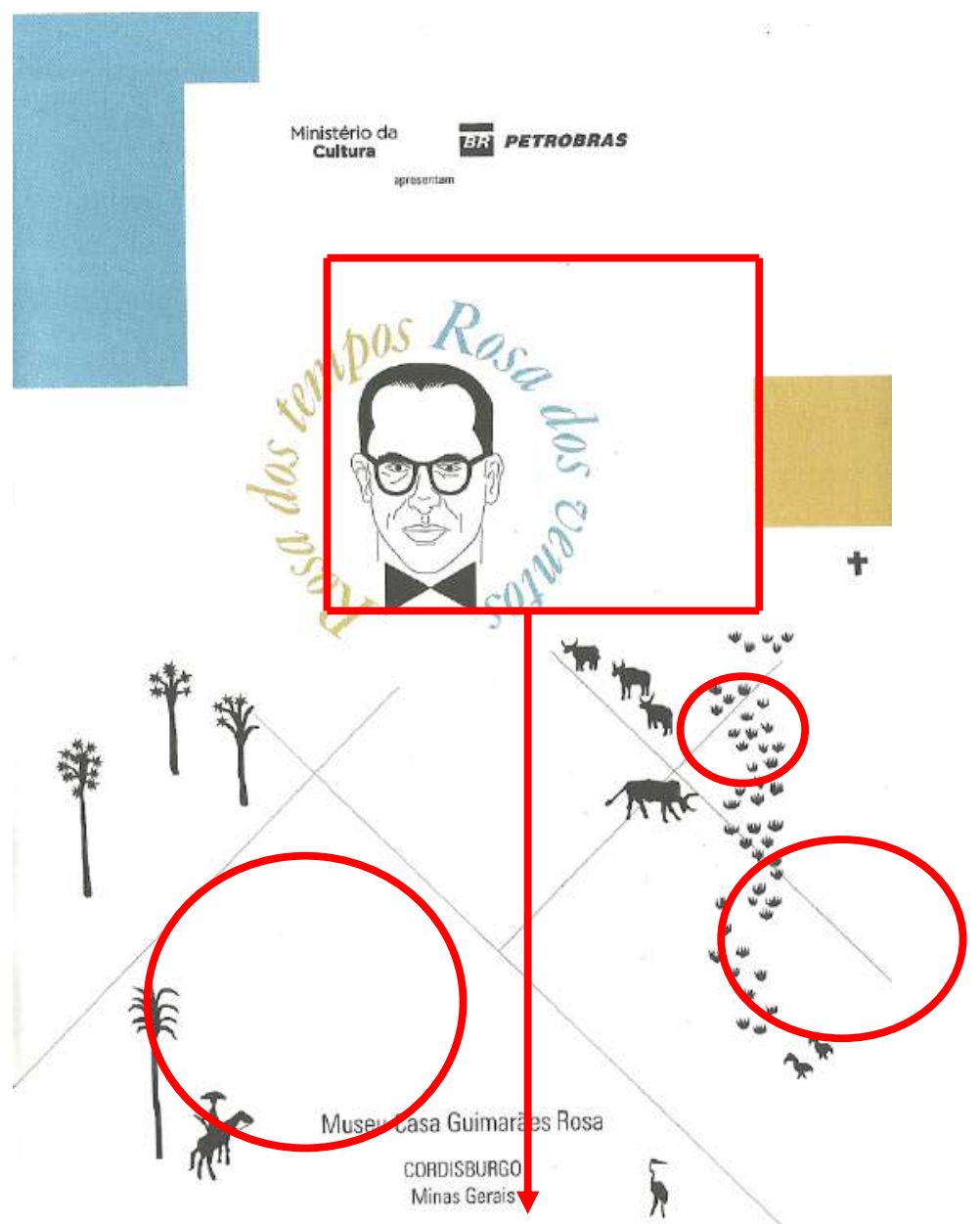

Figura 4 - Panfleto turístico Museu Casa Guimarães Rosa.

Destacamos, primeiramente, a presença da caricatura do próprio Guimarães Rosa, escritor ao qual o museu se refere. Em seu entorno, encontra-se o enunciado "Rosa dos tempos Rosa dos ventos". Esse termo faz alusão à exposição de longa duração presente no museu. Para nós, o fato desse enunciado ser colocado em torno da caricatura do escritor mineiro causa o efeito de curiosidade no público visitante. Dessa forma, acreditamos que esses elementos possuem o funcionamento discursivo de uma logomarca, pois essa estratégia assemelha-se às estratégias utilizadas em discursos publicitários. A particularidade presente no texto do corpus é que se trata de um discurso institucional de um museu referente a uma personalidade da Literatura Brasileira. Novamente, na terminologia 
adotada por Maingueneau (2016), essa cena genérica encontra-se delimitada pelas restrições institucionais.

Além desse fato, podemos visualizar, na imagem que compõe o supracitado folheto turístico, árvores e animais característicos do sertão. Esses traços não verbais se entrelaçam com o seguinte enunciado que introduz o texto presente na segunda seção do panfleto: "'O sertão é do tamanho do mundo.'/Bem-vindo ao mundo mágico do escritor João Guimarães Rosa!". Esse foco no lugar revela a dimensão de a literatura ser um discurso constituinte. Assim, o sertão é visto como uma localidade paradoxal, paratopia, uma vez que ele sintetiza a seguinte condição de um discurso constituinte: sem um local, não há instituições que poderiam legitimar e gerir a produção e o consumo de obras. Entretanto, sem deslocalização, não há verdadeira "constituência" (MAINGUENEAU, 2006). O panfleto turístico utiliza como meio de persuasão essa característica do discurso literário rosiano para projetar institucionalmente a obra de Guimarães Rosa, ressaltando a importância do sertão na verdadeira constituência de sua obra.

Notamos ainda que o discurso institucional não se apresenta de forma independente nesse panfleto turístico. Voltemo-nos agora para as relações entre locutor e interlocutor. Ao estabelecer com seus visitantes o compromisso de divulgar a obra e a vida de Guimarães Rosa, o museu utiliza "artimanhas" da linguagem para interagir com o seu público alvo. Parte dessas "artimanhas" possui relação com o discurso publicitário. Verificamos que os enunciados injuntivos têm um papel relevante no referido folheto publicitário, pois os papéis de locutor/interlocutor foram estabelecidos sob a ótica do modo de organização enunciativo de injunção. É o que se constata em Charaudeau (2012, p. 87):

\section{Papel do locutor:}

- estabelece com seu enunciado uma ação de realizar (“a dizer" ou "a fazer").

- impõe essa ação ao interlocutor (mandar que, ordenar que, intimar a). - atribui a si um estatuto de poder (autoridade absoluta).

\section{Papel do interlocutor:}

- é tido como competente para executar a Injunção ("poder fazer").

- recebe uma obrigação de fazer (ou de dizer) à qual se espera que ele se submeta.

- não tem alternativa, pois qualquer recusa de execução comporta, em diferentes graus, um risco de sanção.

Dentre os trechos que exemplificam esse modo de organização enunciativo de injunção que se imbrica ao discurso institucional, reproduzimos o seguinte.

Descubra a cidade que era do coração do escritor e que entrará no seu. Não deixe de conhecer o projeto sociocultural desenvolvido pela Associação dos Amigos do Museu Casa Guimarães Rosa [...] Desvende os segredos de Riobaldo e Diadorim, cavalgue com Manuelzão, embrenhe pelo sertão de Minas Gerais, descubra essa forma tão peculiar de ser mineiro. Da janela do quarto que era dele, imagine a ansiedade que o menino Joãozito tinha de percorrer e escrever sobre a vista que dela tinha. (grifos nossos)

Portanto, entende-se que o discurso publicitário se encontra presente no panfleto turístico. Isso porque a publicidade pode ser compreendida como um discurso que se materializa 
em um texto, cujo objetivo é divulgar um produto ou serviço. No caso do texto do corpus, notamos que todos esses dados apontados até aqui desempenham a função de estratégias persuasivas. Estas foram utilizadas pela instituição como uma forma de divulgação do museu.

\section{Uma análise discursiva do twitter do STJ}

Mais uma vez tomamos como ponto de partida a noção de discurso institucional (KRIEGPLANQUE, 2014) para constituir o corpus da pesquisa realizada pelo segundo analista de discurso júnior. Durante os encontros do grupo de pesquisa, foi apresentado o artigo de López Muñoz (2016, p. 470-482), da Universidad de Cádiz. Considerando que a atuação política depende também da competência tecnológica dos atores dessa esfera social, o autor analisou um conjunto de tweets produzidos pelo então Presidente da França, François Hollande, entre outubro de 2014 e outubro de 2015. O pesquisador mostrou, em síntese, que as competências em twittescritura de François Hollande são limitadas e que esse campo de estudo é bastante fértil. Por meio de reflexões sobre esse trabalho, decidimos dedicarmo-nos ao estudo da twittescritura, mas a partir da produção desse gênero de discurso no quadro institucional brasileiro: a conta @STJnoticias ${ }^{3}$. Perfil oficial do Superior Tribunal de Justiça, o Tribunal da Cidadania.

Essa página web foi escolhida por ser de fácil acesso e por ter permitido a construção do corpus dessa segunda parte da pesquisa. Nesse sentido, apresentamos a seguir a análise de seis publicações referentes ao primeiro trimestre de 2018, compreendendo os meses de janeiro, fevereiro e março. Foram selecionados dois tweets por mês, sendo um da primeira quinzena, e o outro da segunda quinzena. O referencial teórico-metodológico utilizado foram as categorias de cena englobante e de cena genérica (MAINGUENEAU, 2016). Em relação à cena englobante, procuramos estudar as implicações do lugar da atividade com o fim de classificar o tipo de discurso dominante no caso do Twitter do STJ. Nossa hipótese de trabalho foi a seguinte. Haveria a necessidade de distinguir o lugar virtual e o lugar físico para verificar qual seria a cena englobante predominante dos textos do corpus e como ela restringiria a cena genérica.

Para alcançar esse objetivo, dividimos a análise em dois itens. Em primeiro lugar, dedicamo-nos a diferenciar twitter de tweets com o fim de descrever a cena englobante predominante dos textos do corpus. Em seguida, apresentamos as análises de seis tweets sob a ótica do primado do interdiscurso sobre o discurso associado à noção de cena genérica.

\section{Uma análise discursiva do twitter do STJ: do lugar físico ao lugar virtual}

No estudo de Andrade (2018), compreendemos a importância da análise da cena englobante para associar um lugar (o Conselho de Segurança das Nações Unidas) ao discurso diplomático que se materializou nas intervenções dos representantes permanentes do Brasil, da Espanha e da França. Assim, realizamos o levantamento de dados socio-históricos com o objetivo de visualizar o lugar de onde emergiriam os textos do corpus. Constatamos que o Superior Tribunal de Justiça (STJ) foi criado pela

\footnotetext{
${ }^{3}$ Disponível em https://twitter.com/stjnoticias. Acesso em 22 nov. 2018.
} 
Constituição Federal de 1988 para uniformizar a interpretação da lei federal e que o Twitter foi criado em 2006 pela Obvious Corp. Trata-se de uma das redes sociais mais usadas atualmente (cerca de 9 milhões de usuários mensais), considerada como um microblogging.

Os usuários que se registram no Twitter passam a se valer de uma gama de possibilidades e recursos para interagirem entre si. Por meio das publicações (tweets), cada usuário pode compartilhar mensagens de até 140 caracteres (GUEDES, 2013). Aqueles que o desejarem, poderão ainda reproduzir o tweet de outros usuários, sem alterá-lo. A essa ação, dá-se o nome de retweet. Outro recurso que constitui esse gênero de discurso é o comentário de alguma publicação. Tais comentários podem ser visualizados por todos os membros da rede social e garantir a interação entre os participantes (BARROS; COSTA, 2013). Outra característica marcante do twitter é a possibilidade de se utilizar a \# (hashtag). Por meio do símbolo \#, o usuário consegue criar um link que direciona os usuários a uma nova página, na qual se encontram publicações de outros usuários que também utilizaram aquele termo ou falaram do mesmo assunto. A hashtag foi definida da seguinte forma:

as hashtags classificam, agrupam e direcionam as informações contidas na web sobre os mais variados temas e assuntos, possibilitando maior participação e cooperação dos usuários, através da utilização de palavras-chave para organização. [...] as hashtags são utilizadas não somente para definir e delimitar o conteúdo das informações, como também para exteriorizar ideais, sentimentos, preferências, indignações e posicionamentos variados dos indivíduos que compõem o ciberespaço. [...]. No caso das manifestações fomentadas dentro das mídias sociais, vemos o papel das hashtags em agrupar esses atores virtuais por meio do compartilhamento dos mesmos ideais. (MOURA; MANDAJI, 2014, p. 6-7).

Esses dados arrolados até aqui foram importantes porque eles nos permitiram diferenciar o Twitter do tweet. O primeiro diz respeito à rede social que engloba todos aqueles que interagem por meio de publicações. Para nós, trata-se do suporte. O tweet, por sua vez, diz respeito ao gênero de discurso. Estamos, portanto, diante de um lugar virtual. Ainda que os textos do corpus estejam vinculados ao STJ, percebemos a interação de, pelo menos, duas cenas genéricas predominantes: o discurso jornalístico e o discurso jurídico. Tais reflexões nos levaram a elaborar a seguinte comparação entre a construção composicional dos tweets e o gênero de discurso notícia.

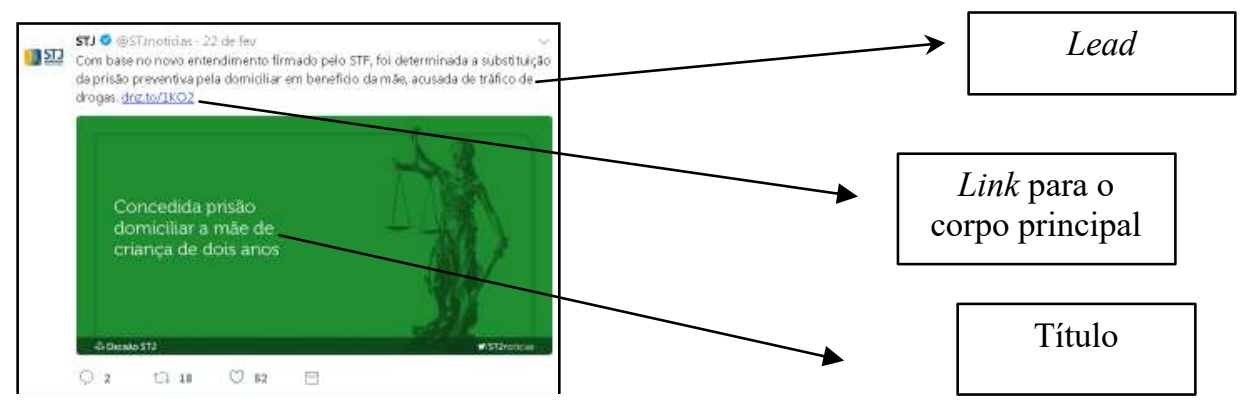

Esquema 1 - Comparação entre tweet e notícia. 
Esse esquema comparativo reforçou a hipótese que lançamos inicialmente de classificar a cena englobante dos textos do corpus como um tipo de discurso jornalístico/midiático, encontrando ainda uma outra justificativa: o número médio de publicações de tweets. Verificamos que ocorrem cerca de 6 ou 8 publicações diárias realizadas pelo STJ. Esse fato corrobora ainda mais o viés midiático/jornalístico, que se compromete com uma certa atualização de informações em pouco tempo. Não obstante, a análise dos textos do corpus levou em consideração a noção de "primado do interdiscurso" sobre o discurso (MAINGUENEAU, 2008), pois trabalhamos com a hipótese de que os tweets abarcariam um conjunto de discursos (interdiscurso), principalmente este conjunto binário advindo da relação institucional do Twitter do STJ: discurso jornalístico/midiático e discurso jurídico. Passemos, pois, ao próximo item dedicado às análises dos textos do corpus.

\section{Análise do corpus: o interdiscurso na cena englobante dos tweets do STJ}

Acabamos de afirmar que há uma interação entre o discurso jornalístico/midiático e o discurso jurídico nos tweets do STJ. Neste item, vamos analisar como a predominância de uma dessas cenas restringe parte do contrato da cena genérica. Para isso, estudaremos o vocabulário enquanto estratégia do jogo imposto por esse quadro institucional ao tweet do STJ, já que, de acordo com Maingueneau (2008), as unidades lexicais tendem a adquirir o estatuto de signos de pertencimento. $\mathrm{O}$ primeiro tweet que apresentamos para análise refere-se à primeira quinzena de janeiro de 2018.

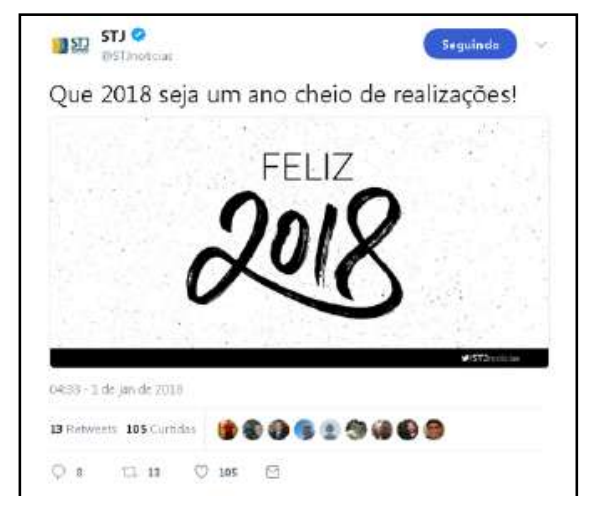

Figura 5 - Tweet da primeira quinzena de janeiro de 2018.

Primeiramente, destacamos o fato de seu tema não estar em consonância com temas mais frequentes do âmbito jurídico, principalmente porque as unidades lexicais presentes no texto tendem a pertencer a discursos festivos. Além disso, a sua publicação ocorreu às 04:33 do dia 1 de janeiro. Esse dado é relevante, pois percebemos que o momento da enunciação contradiz o horário de funcionamento do STJ, como previsto no site, provavelmente por causa de uma restrição temática (mensagens de fim de ano).

O STJ funciona de segunda a sexta-feira, das 11 horas às 19 horas, para atendimento ao público externo (art. $2^{\circ}$ da Resolução n. 34 de 26/10/2012 - DJe 31/10/2012), com exceção do Call Center da Seção de Atendimento ao Cidadão, que funciona das 9 horas às 19 horas, bem 
como do Disque-Cidadania da Ouvidoria, que permite que o usuário externo deixe uma mensagem mesmo fora do horário de atendimento.

O segundo tweet possui algumas diferenças muito sutis em relação ao anterior, pois o discurso jurídico impõe determinadas restrições ao texto materializado pelo referido gênero de discurso. Há uma figura que sublinha estratégias não-verbais de comunicação (cena de ambiente hospitalar). A ela se soma um breve resumo da mensagem que se deseja passar ("hospital é responsabilizado por queimadura em paciente durante cirurgia."). Nesse caso, o termo "responsabilizado" possui coerções do discurso jurídico, já que foi a "Terceira Turma" que responsabilizou um hospital por um dano ao paciente.

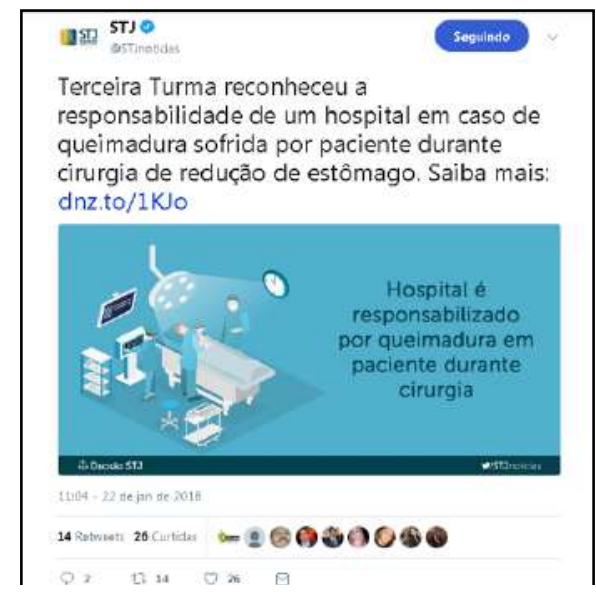

Figura 6 - Tweet da segunda quinzena de janeiro de 2018.

É preciso ressaltar a importante relação entre a expressão "Terceira Turma" e o discurso jurídico. O supremo Tribunal de Justiça possui seis turmas pelo fato dessa instituição ser composta por trinta e três ministros. Estes são escolhidos e nomeados pelo Presidente da República a partir de lista tríplice formulada pelo próprio tribunal. O indicado passa ainda por sabatina do Senado Federal antes da nomeação. Além disso, a Constituição prevê que os ministros tenham origem diversificada: um terço deve ser escolhido entre desembargadores federais, um terço entre desembargadores de justiça e, por fỉm, um terço entre advogados e membros do Ministério Público. Tudo isso evidencia a institucionalização de quem profere a decisão. Ainda que o referido tweet não tenha sido produzido por um desses atores, a presença de suas vozes no texto mostra a interação necessária entre a cena englobante do discurso jurídico com a do discurso jornalístico/midiático. Nesse sentido, a cena genérica segue restrições da referida cena englobante.

Da primeira quinzena de fevereiro de 2018, foi selecionado o seguinte tweet. 


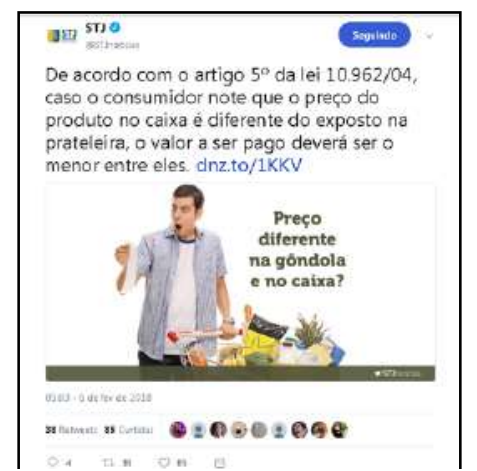

Figura 7 - Tweet da primeira quinzena de fevereiro de 2018.

Nesse terceiro caso, percebemos a união de duas estratégias enunciativas: citação de artigo de lei e sua resolução; e figura que faz alusão a uma situação do dia a dia na qual possa ser aplicado o artigo $5^{\circ}$ da lei 10.962/04. Fica nítida a predominância do discurso jurídico, pois se constata o respeito ao contrato estabelecido imposto pelo referido gênero de discurso institucional: o intertexto evidencia os textos que são produzidos e circula com alguma interferência de determinados atores sociais da referida instituição. Aliás, esse papel institucional de produzir e circular textos conforme suas condições de produção é tão relevante que às vezes podemos encontrar uma relação discursiva interinstitucional. Por isso, passemos para o quarto tweet, referente à segunda quinzena de fevereiro de 2018.

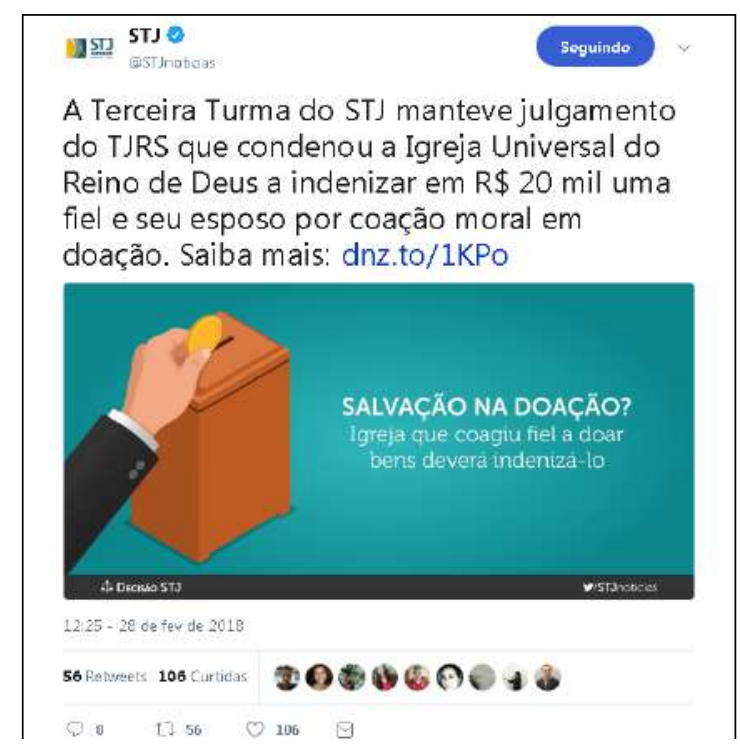

Figura 8 - Tweet da segunda quinzena de fevereiro de 2018.

Há aqui a divulgação de uma decisão da Terceira Turma do STJ. A relação interinstitucional a qual nos referimos anteriormente é estabelecida pelo fato de esse órgão ser responsável por rever julgamentos de outras instâncias jurídicas, no caso o TJRS. Esse dado pode ser inferido a partir do uso de "manteve", que, semanticamente, demonstra essa hierarquia institucional no discurso jurídico por meio de sentidos próprios 
impostos pela referida cena englobante: "julgamento", "condenou", “indenizar" e "coação moral".

O quinto tweet refere-se à primeira quinzena de março de 2018.

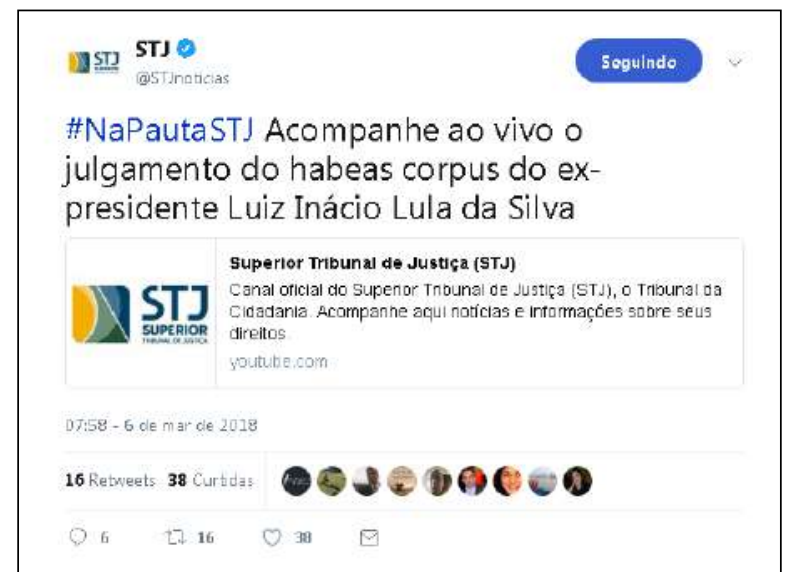

Figura 9 - Tweet da primeira quinzena de março de 2018.

Nessa publicação, percebemos a adesão do STJ Notícias à ferramenta de hashtag. Vimos que, de acordo com Moura e Mandaji (2014, p. 6), as hashtags possibilitam "o agrupamento de postagens por tópicos, articulando determinadas palavras, frases ou expressões precedidas pelo símbolo sustenido “\#”, chamado hashtag”. Entendemos que esse recurso também permite agrupar assuntos e pessoas que possuem um mesmo ideal, como se pode notar, por exemplo, nos trabalhos de Recuero, Zago e Bastos (2014) e Silveira (2015). No caso do tweet apresentado, a hashtag \#NaPautaSTJ possibilitou o agrupamento de postagens em torno do habeas corpus do ex-presidente Luiz Inácio Lula da Silva. Logo, por meio dela, vimos, em nossos encontros, que diferentes indivíduos foram interpelados em sujeitos por diversas ideologias (ORLANDI, 2015). Estas puderam ser observadas e discutidas com base nesta relação interdiscursiva: discurso jurídico garantista, discurso jurídico punitivista, discurso político de direita, discurso político de esquerda etc. Além disso, indicamos o uso do modo imperativo em "acompanhe" para que o leitor observe a frequência das publicações e assista o julgamento mencionado. Por último, observamos que o termo "habeas corpus" é mais um elemento semântico que segue as restrições do discurso jurídico.

Por fim, apresentamos o último tweet, referente à segunda quinzena de março de 2018.

Nessa última publicação, o primeiro ponto ao qual nos atentamos é o direcionamento do discurso por meio de "você", no início da seguinte pergunta: "você sabe qual é a composição do Superior Tribunal de Justiça?" O uso desse pronome pode indicar uma certa proximidade/conexão entre enunciador e enunciatário. A referida pergunta é respondida logo abaixo com o auxílio de um esquema montado numa lousa branca (novamente, lança-se mão de recursos não verbais). Constata-se, pois, o entrelaçamento do discurso jurídico com o discurso pedagógico. Este, porém, não predomina no tweet, porque o seu fim é persuadir os "concurseiros" a formarem parte dessa instituição jurídica. 


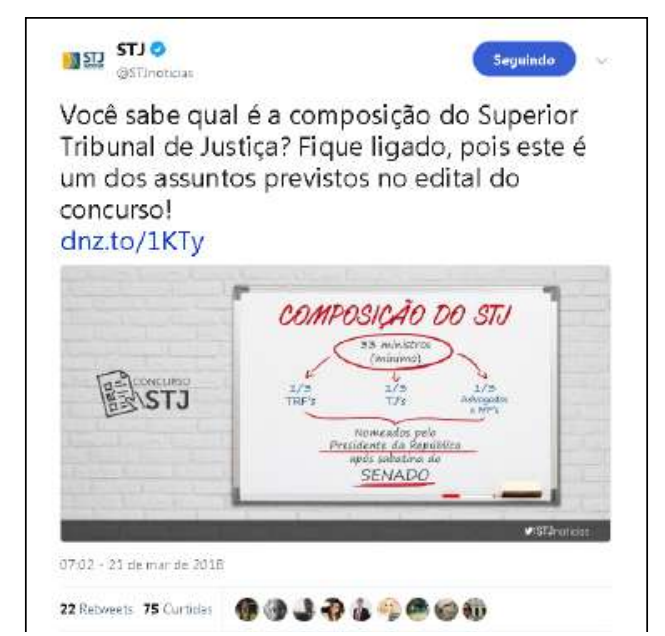

Figura 10 - Tweet da segunda quinzena de março de 2018.

\section{CONCLUSÃo}

As análises apresentadas demonstram o engajamento dos analistas de discurso juniores no fazer científico dentro do campo dos Estudos Linguísticos. No que diz respeito ao estudo do discurso institucional presente na análise do Museu Casa Guimarães Rosa, a pesquisa teve um resultado relevante, até mesmo por estabelecer uma ligação direta com a vida e a obra do escritor Guimarães Rosa, tornando interessante a análise das diferentes características discursivas atribuídas principalmente a uma instituição como o museu.

Em relação ao estudo do gênero de discurso tweet do STJ, realizou-se uma série de questionamentos iniciais que poderiam ser considerados simplórios e modestos num contexto trivial ou de sala de aula. Entretanto, foi compreendido que faz parte do trabalho do analista de discurso júnior desdobrar-se sobre aquilo que é, na maioria das vezes, considerado óbvio. Nesta pesquisa, percebemos que são realizados aprofundamentos sobre questões triviais. Com isso, diferentes visões metodológicas vieram à tona, auxiliando a interpretação do referido fenômeno discursivo.

Conclui-se que a inauguração do Grupo de Pesquisa sobre o Discurso Institucional na Iniciação Científica e Tecnológica com os dois estudos apresentados aqui teve fundamental importância na formação de dois jovens cientistas no Ensino Básico. Tratase de uma contribuição modesta, sobretudo quando pensamos em eventos como a Feira de Ciências que ocorre há tantos anos no Ensino Básico, quase sempre sem a presença de professores-pesquisadores da área de Letras. No entanto, esses exemplos poderiam ser tomados como um meio de fomentarmos a formação de analistas de discurso juniores, inclusive a partir das mais variadas vertentes da Análise do Discurso.

\section{REFERENCIAS}

ANDRADE, Rafael Batista. Caracterização de um gênero de discurso diplomático: as intervenções dos representantes permanentes do Brasil, da Espanha e da França no Conselho de Segurança da Nações Unidas (CSNU). Tese. Doutorado em Estudos Linguísticos. Faculdade de Letras da Universidade Federal de Minas Gerais, Belo Horizonte, 2018. 
ANDRADE, Rafael Batista. Semiótica, éthos e gêneros de discurso nas canções-poemas de Maria Bethânia. Curitiba: CRV, 2015.

BAKHTIN, Mikhail. Estética da criação verbal. 6 $^{\text {a }}$ ed. São Paulo: Martins Fontes, 2011.

BARROS, A.K.; COSTA, M.H. Oralidade e escrita: o hibridismo no Twitter. Entrepalavras, Fortaleza, v. 3, n. 1, 100-107, 2013.

CHARAUDEAU, P. Linguagem e discurso: modos de organização. São Paulo: Contexto, 2012. CHARAUDEAU, P.; MAINGUENEAU, D. Dicionário de análise do discurso. $2^{\mathrm{a}}$. ed. São Paulo: Contexto, 2008.

GUEDES, T.M. As redes sociais - Facebook e Twitter - e suas influências nos movimentos sociais. Brasília: Universidade de Brasília, 2013.

KRIEG-PLANQUE, Alice. Analyser les discours institutionnels. Paris: Armand Colin, 2014. KERBRAT-ORECCHIONI, C. O ethos em todos os seus estados. Em: MACHADO, I.L.; MELLO, R. de. (Orgs.). Análises do discurso hoje. v. 3. Rio de Janeiro: Nova Fronteira, 2010. LÓPEZ MUÑOZ, Juan Manuel. Tweets politiques et image de twitteur: l'exemple de @fhllande. In: CONCUERA, J. Fidel et. al. (Coord.). Les discours politiques: regards croisés. Paris: L'Harmattan, 2016. p. 470-482.

MAINGUENEAU, D. Analyser les textes de communication. Paris: Armand Colin, 2016. MAINGUENEAU, D. La philosophie comme institution discursive. Limoges: Lambert-Lucas, 2015.

MAINGUENEAU, D. Gênese dos discursos. Trad. Bras. São Paulo: Parábola, 2008.

MAINGUENEAU, Dominique. Discurso Literário. São Paulo: Contexto, 2006.

MARCUSCHI, L.A. Produção textual, análise de gêneros e compreensão. São Paulo: Parábola, 2008.

MOURA, K. F., MANDAJI, C.F. A relação das hashtags com as palavras de ordem presentes nas Manifestações Brasileiras de 2013. Intercom - Sociedade Brasileira de Estudos Interdisciplinares da Comunicação. Palhoça, SC: Intercom, 2014.

ORLANDI, E.P. Análise de discurso: princípios e procedimentos. São Paulo: Pontes, 2015.

RECUERO, R.; ZAGO, G.; BASTOS, M.T. O discurso dos \#ProtestosBR: análise de conteúdo do Twitter. Galáxia, São Paulo, n. 28, 199-216, dez. 2014. Disponível em http://www.scielo.br/pdf/gal/v14n28/v14n28a17.pdf. Acesso em 09 dez. 2020.

SARFATI, Geroges-Elia; PAVEAU, Marie-Anne. Les grandes théories de la linguistique: de la grammaire comparée à la pragmatique. Babneux, Numilog, 2014.

SILVEIRA, Juliana da. Rumor(es) e humor(es) na circulação de hashtags do discurso político ordinário no Twitter. Tese. Doutorado em Estudos Linguísticos. Centro de Ciências Humanas, Letras e Artes da Universidade Estadual de Maringá, 2015.

Artigo recebido em: nov. de 2018.

Aprovado e revisado em: maio de 2019.

Publicado em: dezembro de 2019.

Para citar este texto:

ANDRADE, Rafael Batista. O discurso institucional na iniciação científica e tecnológica: Museu Casa Guimarães Rosa e STJ sob a ótica de analistas de discurso juniores. Entremeios [Revista de Estudos do Discurso, ISSN 2179-3514, on-line, www.entremeios.inf.br], Seção Estudos, Programa de Pós-Graduação em Ciências da Linguagem (PPGCL), Universidade do Vale do Sapucaí (UNIVÁS), Pouso Alegre (MG), vol. 18, p. 63-80, jan. - jun. 2019.

DOI: http://dx.doi.org/10.20337/ISSN2179-3514revistaENTREMEIOSvol18pagina63a80 